\title{
Discite secundária à infecção urinária: relato de caso
}

\author{
Discitis secondary to urinary tract infection: case report
}

Thalita Carvalho Nagib ${ }^{\dagger}$, Carla Maria Nogueira Cavalheiro†, Thaísa Suckow Custódio ${ }^{\dagger}$, Girley Cordeiro de Souza

Como citar esse artigo. Nagib, T.C.;

Cavalheiro, C.M.N.; Custódio, T.S.;

Souza, G.C. Discite secundária à infecção urinária: relato de caso. Revista de Saúde. 2020 Jan./Jun.; 11 (1): 15-20.

\section{Resumo}

Discite por definição trata-se de um processo inflamatório, em sua grande maioria infeccioso, que acomete os discos intervertebrais, causando como principal sintoma a dor, que pode localizar-se na coluna ou irradiar para locais como abdome, quadris, membros inferiores ou virilha devido a compressão das raízes nervosas. É uma causa relativamente rara de lombalgia no adulto, afetando mais o sexo masculino e predominando na faixa etária entre 50 e 60 anos. Sintomas como febre, acompanhada de calafrios e sudorese noturna são comemorativos importantes na história clínica do paciente que ajudam a alcançar o diagnóstico. O relato de caso trata de um idoso de 74 anos, com história de hipoestesia e paraparesia importante em membros inferiores, associado a febre e calafrios raros, diagnosticado com discite secundária à uma infecção urinária por Enterococcus spp., baseado na história do paciente, sintomas clínicos e achados de imagem. Destacam-se a importância e o desafio do diagnóstico precoce, indicando os sintomas muitas vezes inespecíficos, que necessitam estar acompanhados de uma coleta rigorosa da história clínica do paciente, com o manuseio correto dos exames de imagem e laboratoriais, identificando o agente infeccioso implicado para um tratamento eficaz e conduzido pela cultura, fornecendo um melhor prognóstico clínico e maior sobrevida dos pacientes.

Palavras-chave: discite infecciosa; infecção urinária; Enterococcus spp.

\begin{abstract}
Discitis by definition is an inflammatory process, mostly infectious, that affects the intervertebral discs, causing pain as the main symptom, which can be located in the spine or radiate to places such as the abdomen, hips, lower limbs or groin due to compression of the nerve roots. It is a relatively rare cause of low back pain in adults, affecting more males and predominating in the age group between 50 and 60 years. Symptoms such as fever accompanied by chills and night sweats are important events in the patient's medical history that help to reach the diagnosis. This study reports a case of a 74-year-old man, with a history of hypoaesthesia and significant paraparesis in the lower limbs, associated with fever and rare chills, diagnosed with discitis secondary to a urinary infection by Enterococcus spp., based on the patient's history, clinical symptoms and imaging findings. The importance and challenge of early diagnosis is demonstrated, indicating symptoms that are often nonspecific, which need to be accompanied by a rigorous collection of the patient's clinical history, with the correct handling of imaging and laboratory tests, detecting the infectious agent involved for a correct and culture-oriented treatment, generating a better clinical prognosis and longer patient survival.
\end{abstract}

Keywords: infectious discitis; urinary infection; Enterococcus spp.

\section{Introdução}

Discite por definição trata-se de um processo inflamatório, em sua grande maioria infeccioso, que atinge os discos intervertebrais e suas respectivas vértebras. ${ }^{1}$ A disseminação pode ocorrer por via hematogênica, contiguidade, ou por inoculação percutânea. $^{2}$ O Staphylococcus aureus e as enterobactérias estão presentes na literatura como os responsáveis por mais de $50 \%$ dos casos de discite, quando não relacionados à tuberculose, sendo este primeiro o agente mais comumente isolado. ${ }^{1}$

Um grande desafio encontrado diante desta patologia é o diagnóstico precoce, pois em sua grande maioria é retardado ou até esquecido devido à raridade da doença e pela elevada incidência de lombalgia na população em geral, principalmente quando relacionado ao envelhecimento fisiológico. ${ }^{2}$ É possível observar em cerca de um terço dos pacientes, déficits neurológicos como fraqueza em membros inferiores, radiculopatias, paralisia, incontinência esfincteriana e déficit sensorial. ${ }^{3}$ A sintomatologia, normalmente inicia-se de forma insidiosa, e sintomas que são considerados de "bandeira vermelha" que marcam a doença englobam: dor contínua, geralmente localizada na coluna ou irradiada para locais como membros inferiores, abdome, quadris

\footnotetext{
Afiliação dos autores:

$†$ Pró-Reitoria de Ciências da Saúde, Discente do curso de Medicina, Universidade de Vassouras - Vassouras, RJ, Brasil.

\$ Pró-Reitoria de Ciências da Saúde, Docente do curso de Medicina, Universidade de Vassouras - Vassouras, RJ, Brasil.
}

*Email de correspondência: thata_nagib@yahoo.com.br 
e virilha devido à compressões nervosas, piorando à noite. ${ }^{2}$ Febre acompanhada de calafrios constitui um quadro extremamente importante para o diagnóstico, que juntamente com os sintomas radiculares, evidencia uma origem infecciosa, e está presente em $50 \%$ dos casos, menos comumente nas discites secundárias a tuberculose. ${ }^{3}$

Os achados laboratoriais, da mesma forma que as manifestações clínicas, são muito inespecíficas para o diagnóstico, mas importantes para prognóstico. Uma leucocitose pode ocorrer em apenas $33 \%$ dos casos, não apresentando muito valor diagnóstico, podendo apenas indicar uma infecção existente. ${ }^{1}$ A realização da hemocultura com antibiograma é de extrema importância na vigência da suspeita de infecção, pois além de confirmar o agente bacteriano envolvido, também auxilia na antibioticoterapia a ser utilizada. A ressonância magnética é o exame de imagem de escolha, pois possibilita a avaliação de alterações dos discos intervertebrais, das vértebras e dos tecidos moles circundantes. ${ }^{4}$ Também é eficaz em distinguir entre discite piogênica, de neoplasia e tuberculose. ${ }^{5}$ As dosagens séricas da proteína $\mathrm{C}$ reativa $(\mathrm{PCR})$ e da velocidade de hemossedimentação (VHS) são exames simples, e suas dosagens seriadas são comumente usadas e determinantes para estimar a resposta do paciente durante o tempo de tratamento. ${ }^{1}$

Inicia-se o tratamento de forma conservadora, utilizando algumas medidas não farmacológicas e antibioticoterapia sempre que possível acompanhada por culturas com antibiograma. ${ }^{6}$ Intervenções cirúrgicas são indicadas quando há compressão de elementos neurais, cifose grave, instabilidade da coluna vertebral devido à grande destruição óssea, ou falha do tratamento de forma conservadora. ${ }^{2}$

Este trabalho tem como objetivo relatar um caso de discite secundária a uma infecção urinária por Enterococcus spp., em um idoso de 74 anos, destacando a importância e o desafio do diagnóstico precoce, já que os sintomas são muitas vezes inespecíficos, e necessitam estar acompanhados de uma coleta rigorosa da história clínica do paciente, associado a uma alta suspeição, com o manuseio correto dos exames laboratoriais e de imagem, identificando o agente infeccioso implicado para um tratamento eficaz e conduzido pela cultura, fornecendo um melhor prognóstico clínico e maior sobrevida dos pacientes.

\section{Relato de caso}

Paciente do sexo masculino, 74 anos, branco, hipertenso em uso de enalapril $10 \mathrm{mg}$, hidroclorotiazida $25 \mathrm{mg}$, gabapentina $400 \mathrm{mg}$, pregabalina $75 \mathrm{mg}$ e tramadol $100 \mathrm{mg}$ SOS, com relato de que ao final de 2017 iniciou um quadro de hipoestesia em ambos os membros inferiores e paraparesia, associado também à dor de caráter pulsátil na mesma localidade, acompanhada de raros episódios de calafrios e sudorese noturna. Em razão disso, procurou por um médico ortopedista no mesmo ano para alívio dos sintomas, acreditando ser de origem óssea. Após a avaliação do médico ortopedista, foram prescritos analgésicos comuns para alívio das dores, cuja posologia não se recordava para informar à equipe, e encaminhado a algumas sessões de fisioterapia, que não obtiveram sucesso, uma vez que os sintomas tornaram-se progressivos, dificultando sua movimentação.

Observando a gravidade do caso, o paciente procurou ao final de 2018 por um médico neurologista, que após tomar ciência de um histórico de prostatectomia há 07 anos em razão de um câncer de próstata, solicitou uma cintilografia de toda a coluna procurando por implantes metastáticos como a causa do quadro clínico. No entanto, a cintilografia não demonstrou nenhum resultado que confirmasse sua hipótese.

Quando foi então referenciado ao Hospital Municipal Luiz Gonzaga (HMLG) em Miguel Pereira RJ, no segundo semestre de 2019, para ser atendido na média complexidade, por especialistas. Neste serviço de saúde, se constatou após rigorosa coleta da história clínica, um histórico de infecção de urina de repetição há 03 anos, tratado com diversos antibióticos cujos

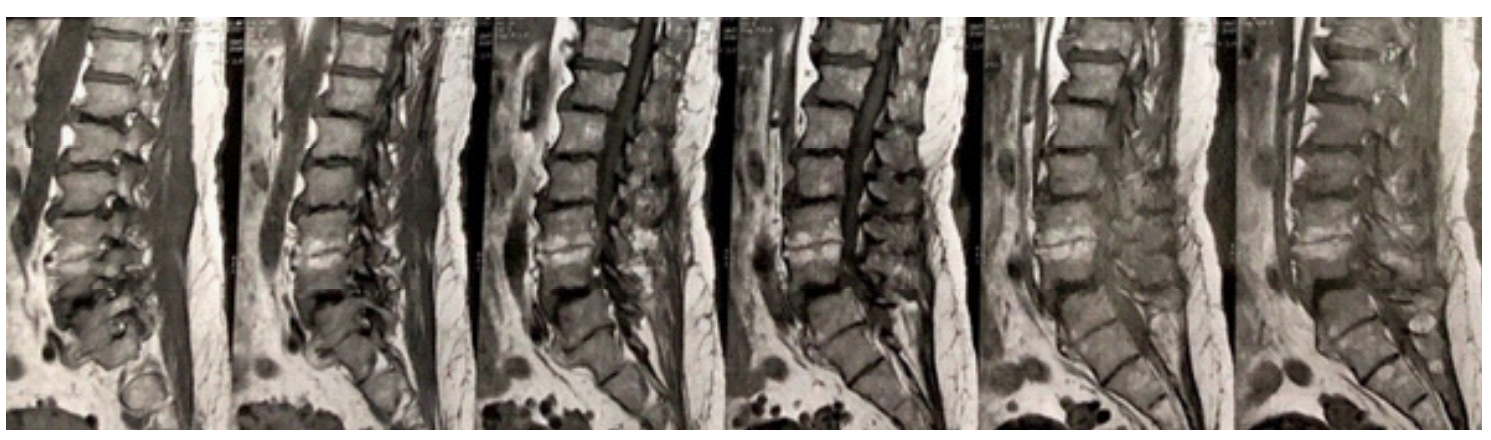

Figura 1. Ressonância magnética de coluna lombar demonstrando inflamação do disco intervertebral com acometimento do platô das vértebras acima e abaixo. 


\section{Material..: Urina \\ UROCULTURA COM ANTIBIOGRAMA \\ Método: CULTIVO EM MEIOS ESPECIFICOS \\ RESULTADO: \\ CULTURA QUANTITATIVA: ACIMA DE $100.000 \mathrm{UFC/mL}$ CULTURA QUALITATIVA: ISOLADO: ENTEROCOCCUS SPP \\ ANTIBIOGRAMA REFERENTE A ENTEROCOCCUS SPP \\ SENSIVEL A: \\ Penicilina \\ Nitrofurantoin \\ Ampicilina \\ AmoxJAc.Clavulanic \\ Fosfomicina \\ VALOR DE REFERENCIA: AUSENCIA DE CRESCIMENTO BACTERIANO.}

Figura 2. Resultado do exame de urocultura com antibiograma.

nomes e posologias não se recordava para informar à equipe. Ao exame neurológico o paciente apresentava hipoestesia em ambos os membros inferiores, com diminuição importante do reflexo aquileu à direita. Foi então que o neurocirurgião responsável, solicitou uma ressonância magnética da coluna (figura 1) suspeitando de discite infecciosa secundária à infecção urinária.

Ao correlacionar a história clínica do paciente e o exame de imagem agora conclusivo, corroborando sua hipótese diagnóstica, o médico responsável solicitou sua internação no dia 19/08/2019 para detectar o agente bacteriano envolvido através de uma urocultura com antibiograma (figura 2) e iniciar o tratamento baseado nos resultados.

Identificado o Enterococcus spp. como o agente isolado, sendo o mesmo sensível, iniciou-se então o tratamento com ampicilina $1 \mathrm{~g} \mathrm{EV} \mathrm{6/6h} \mathrm{por} 28$ dias. Foi realizada também dosagem semanal dos valores de PCR e VHS séricos.

Ao final da primeira semana de tratamento (28/08/2019), o paciente já apresentava melhora da dor, porém permanecia em decúbito dorsal na maior parte do tempo, pois a movimentação acentuava a dor. Queixouse de epigastralgia importante, relacionada ao uso da gabapentina e pregabalina, e por isso, foi acrescentado em sua prescrição diária ranitidina $50 \mathrm{mg} \mathrm{EV} \mathrm{12/12h.}$
Foram observados os valores de PCR e VHS contidos na tabela 1 ao final da primeira semana.

Em sua segunda semana de tratamento (04/09/2019), apresentava melhora importante da dor, inclusive sem sinal de Lasègue pela primeira vez durante a internação. Estava apto a deambular sem auxílio, relatando pouca dor, que aparecia principalmente ao fazer os movimentos de sentar e levantar. Foram observados os valores de PCR e VHS contidos na tabela 1 ao final da segunda semana.

Logo ao final da terceira semana de tratamento (11/09/2019), manteve melhora da dor, queixando-se apenas de "formigamento e sensação de várias agulhas nos pés" antes de dormir. Foram observados os valores de PCR e VHS contidos na tabela 1 ao final da terceira semana.

Ao término do tratamento, no dia 18/09/2019, o paciente relatou melhora considerável dos sintomas, já sendo capaz de deambular e tomar banho sem auxílio. Foram observados os valores de PCR e VHS contidos na tabela 1 ao final da quarta semana. Continuou necessitando de analgésicos esporádicos, porém relatou ter um aumento importante na qualidade de vida.

Foi encaminhado então para um acompanhamento fisioterápico rigoroso, uma vez que a inflamação local já havia se reduzido, deixando livre os forames neurais, sem causar dor. Ressaltou-se que devido sua idade avançada, é possível que a dor não desapareça por completo, permanecendo dor crônica residual, uma das complicações mais comuns da doença. Recebeu também um encaminhamento ao serviço de urologista para prevenção, tratamento e acompanhamento dos episódios de infecção de urina de repetição, na tentativa de evitar recidiva da discite infecciosa.

O paciente vem evoluindo de modo satisfatório, mantendo acompanhamento ambulatorial, sessões de fisioterapia regulares e em tratamento contínuo para profilaxia de infecção urinária com nitrofurantoína 100 mg $1 \mathrm{vez}$ ao dia durante 03 meses. Encontra-se pouco sintomático e satisfeito com o tratamento instituído.

Tabela 1. Valores da proteína C reativa (PCR) e velocidade de hemossedimentação (VHS) ao decorrer das 4 semanas de tratamento.

\section{Semanas de tratamento}

\begin{tabular}{lllll}
\hline & $\mathbf{1}^{\circ}$ semana & $\mathbf{2}^{\circ}$ semana & $\mathbf{3}^{\circ}$ semana & $\mathbf{4}^{\circ}$ semana \\
PCR & $12 \mathrm{mg} / \mathbf{n}$ & Negativo & Negativo & Negativo \\
VHS 1 & & & \\
& $23 \mathrm{~mm}$ & $13 \mathrm{~mm}$ & $30 \mathrm{~mm}$ & $09 \mathrm{~mm}$ \\
\hline
\end{tabular}




\section{Discussão}

A espondilodiscite infecciosa não se trata de uma doença atípica na população mundial, sua incidência por ano varia de 0,5 a 2,5 casos por 100.000 habitantes. ${ }^{5}$ É considerada a segunda principal causa de infecção vertebral no mundo, perdendo apenas para a tuberculose. $\mathrm{O}$ fator de risco habitualmente encontrado entre os pacientes portadores é o diabetes melito, mas também é possível citar outros, como idade avançada, pacientes imunossuprimidos, usuários de drogas injetáveis, malignidade, insuficiência renal, doenças reumáticas, cirrose hepática e realização de cirurgia prévia em medula espinhal. ${ }^{2}$

A contaminação vertebral ocorre basicamente através de três maneiras: disseminação hematogênica, inoculação percutânea direta ou por contiguidade. A via mais comumente envolvida é a hematogênica, atingindo principalmente a coluna lombar (58\%), torácica $(30 \%)$ e cervical (11\%). Em mais da metade dos casos de discite, identifica-se o foco infeccioso à distância, destacando-se em: trato geniturinário (17\%), endocardite infecciosa (12\%), pele e tecidos moles (11\%), próteses endovasculares $(5 \%)$, trato gastrintestinal $(5 \%)$, trato respiratório (2\%) e cavidade oral $(2 \%){ }^{7}$

Em aproximadamente $50 \%$ dos casos, é possível isolar o Staphylococcus aureus como o agente bacteriano causador, tendo destaque em pacientes com mais de 50 anos de idade, sem um foco aparente de infecção e sem história de internação hospitalar recente. Escherichia coli, Klebsiella spp., Proteus spp. e Enterobacter spp. estão geralmente relacionados a infecções do trato urinário e a idade mais avançada, o Streptococcus viridans e os beta-hemolíticos dos grupos A e B encontram-se associados à endocardite infecciosa. ${ }^{8}$

$\mathrm{O}$ paciente deste relato, queixou-se de uma história de infecção urinária de repetição nos últimos 03 anos, que possibilitou a contaminação por contiguidade da coluna lombar, onde a inflamação dos discos intervertebrais com a compressão dos forames neurais, possibilitou observar os sintomas radiculares relatados, sendo estes muito comumente encontrados em casos similares. ${ }^{7}$

O diagnóstico é fundamentado em sintomas clínicos, achados laboratoriais e de imagem, e pode ser de difícil acurácia por se tratar de achados não específicos. Em alguns casos, o diagnóstico pode ser atrasado ou até mesmo esquecido devido ao pouco conhecimento da doença, aos sintomas que aparecem vagarosamente e à alta frequência de lombalgia na população em geral, confundindo com alterações ósseas fisiológicas do envelhecimento. ${ }^{2}$ Em estudos recentes, observou-se que a evolução dos sintomas geralmente se desdobra entre 1-2 meses, sendo que o tempo médio decorrido entre a chegada ao hospital e a definição do diagnóstico gira em torno de 4 dias. ${ }^{9}$

No caso descrito, o paciente passou por outras especialidades como ortopedia, imaginando tratar-se de uma dor de origem óssea, muscular, ou até mesmo sintomas comuns da idade avançada, retardando assim seu diagnóstico. Porém com a acentuação dos sintomas, prosseguiu sua investigação para melhor manejo do caso.

$\mathrm{Na}$ discite infecciosa, as manifestações clínicas geralmente surgem forma lenta, com dor lombar ou cervical contínua, que se acentua no período noturno e pode irradiar-se para o peito, abdome, quadril, membros inferiores e virilha. ${ }^{2}$ A febre pode ser identificada em $50 \%$ dos casos, podendo ser acompanhada de calafrios, e os déficits neurológicos, presentes em um terço dos pacientes, incluem fraqueza nos membros inferiores, déficit sensorial, radiculopatias, paralisia e incontinência esfincteriana. ${ }^{7}$ Os sintomas apresentados pelo paciente relatado, foram hipoestesia e paraparesia, com dor de caráter pulsátil em ambos os membros inferiores, mostrando ter origem radicular, possivelmente compressiva. Acrescido de febre, com calafrios raros, o que sugeriu com mais clareza o quadro infeccioso.

Os achados laboratoriais, da mesma forma que os sintomas clínicos, são muito inespecíficos para o diagnóstico, mas importantes para o prognóstico. Uma leucocitose pode ocorrer em apenas 33\% dos casos, não apresentando muito valor diagnóstico, podendo apenas indicar uma infecção existente. ${ }^{1}$ Por outro lado, a sensibilidade, especificidade e acurácia da Ressonância Magnética no diagnóstico atingem 96, 93 e $94 \%$, respectivamente. ${ }^{4}$ A realização da cultura com antibiograma se mostra importante para detectar a bactéria em questão e guiar de forma correta o tratamento. O diagnóstico de certeza do caso relatado só foi possível através da RMN realizada pelo paciente, acompanhada da urocultura com antibiograma, onde evidenciou-se o agente etiológico Enterococcus spp. para um tratamento direcionado.

A PET-CT tem sido utilizada recentemente com progressivas documentações na literatura, onde se comprova ser um método promissor no diagnóstico da doença. Este exame apresenta uma elevada sensibilidade na distinção entre tumores malignos, hérnias discais, processos inflamatórios, implantes metálicos e próteses, onde a RMN tem uma especificidade diagnóstica mais baixa. $^{9}$

Objetiva-se no tratamento da discite infecciosa a erradicação da infecção, aliviando os sintomas, restabelecendo a função, e preservando as estruturas próximas. O tratamento conservador baseia-se em medidas não farmacológicas, como acompanhamento fisioterápico e imobilização, acompanhadas do uso de analgésicos e antibióticos. ${ }^{2} \mathrm{~A}$ antibioticoterapia deve ser iniciada após o resultado da hemocultura ou da biópsia da lesão, salvo nos casos de sepse grave, onde inicia-se 
obrigatoriamente uma antibioticoterapia empírica até o resultado do antibiograma. ${ }^{6}$ Intervenções cirúrgicas são indicadas quando há compressão de elementos neurais, cifose grave, instabilidade da coluna vertebral devido à grande destruição óssea, ou falha do manejo de forma conservadora. $^{2} \mathrm{O}$ tratamento instituído ao paciente relatado, foi baseado na urocultura com antibiograma, evidenciando infecção pelo agente etiológico Enterocccus spp., sendo o mesmo sensível a ampicilina, que foi o antibiótico de escolha utilizado, na posologia de $1 \mathrm{~g}$ por via endovenosa de $6 / 6 \mathrm{~h}$, durante 28 dias.

Alguns marcadores são extremamente úteis, não para o diagnóstico, mas sim para o prognóstico e evolução do tratamento. A velocidade de hemossedimentação (VHS) é um marcador muito sensível para infecção, porém apresenta baixa especificidade. Em muitos relatos, a mesma encontra-se elevada em mais de $90 \%$ dos casos de discite. Em questão de prognóstico, observar-se uma queda na VHS de um quarto do valor apresentado, é considerado um resultado extremamente positivo. Assim, uma VHS que permanece estabilizada ou em ascensão durante o tratamento reflete uma maior dificuldade na interpretação, sendo então aconselhável avaliar esse marcador juntamente com outros parâmetros. ${ }^{2}$ A proteína $\mathrm{C}$ reativa (PCR) se mostra semelhantemente aumentada em uma grande porcentagem dos casos de discite. É citada por vários autores como o marcador favorito para monitorizar a resposta ao tratamento. ${ }^{6}$ Neste relato, foi possível observar a queda do VHS, com oscilação na terceira semana, pois tratando-se de um marcador sensível, é possível ter seu valor alterado por outras condições. Já o PCR, teve seu valor negativado já na segunda semana de antibioticoterapia, mostrando uma ótima resposta ao tratamento.

Em junho de 2019, a Sociedade Brasileira de Medicina Hiperbárica relatou em suas Diretrizes de Uso da Oxigenoterapia Hiperbárica, o benefício do uso da técnica em pacientes com espondilodiscite de coluna vertebral, sendo esta indicada em (1) pacientes com diagnóstico estabelecido, submetidos ao tratamento convencional (clínico e/ou cirúrgico) por 30 dias, com ou sem remoção de implantes existentes, sem resposta terapêutica adequada; (2) pacientes com espondilodiscite associada à comorbidades ou situações clínicas agravantes como diabetes, septicemia, abscessos, lesões osteolíticas extensas, etc. ${ }^{10}$

Os critérios de cura diante do tratamento instituído compreendem a ausência ou melhora dos sintomas e a regularização dos valores do PCR ou VHS. ${ }^{2}$ $\mathrm{O}$ prognóstico dos pacientes normalmente evolui de forma satisfatória, tendo seguimento do tratamento com acompanhamento fisioterápico rigoroso, e resolução do quadro infeccioso original que teve como resultado a discite.

Este relato de caso apresenta um idoso de 74 anos, que evoluiu de forma favorável mediante o tratamento instituído, sem a necessidade de abordagem cirúrgica. Relatou melhora importante da dor e dos sintomas radiculares, encontrando-se pouco sintomático, porém satisfeito com os resultados. Mantém-se em acompanhamento fisioterápico, e em tratamento profilático para infecção de urina de repetição com nitrofurantoína $100 \mathrm{mg} 1 \mathrm{vez}$ ao dia durante 03 meses.

\section{Considerações finais}

Conclui-se então, que a discite infecciosa se trata de uma doença mais insidiosa, comum na população de idade avançada e com uma baixa taxa de mortalidade, porém alta morbidade. Com o melhor conhecimento dos seus sintomas e achados na história clínica, é possível incluir essa patologia nos diagnósticos diferenciais de lombalgia, acelerando o seu diagnóstico, a fim de assegurar melhores resultados a longo prazo. Mas para isso, um alto índice de suspeição é necessário, pois o diagnóstico precoce ainda é considerado um enorme desafio, justificando a necessidade da abordagem deste tema.

Uma maior compreensão e o uso precoce da ressonância magnética nos casos suspeitos, são indispensáveis para evitar um retardo no início do tratamento. $\mathrm{O}$ início da terapia antimicrobiana precocemente, e sua utilização prolongada, com a seleção do antibiótico correto baseado em amostras de cultura com antibiograma imediatamente colhidos após o diagnóstico, e a aplicação cautelosa de abordagens cirúrgicas adequadas são essenciais para a obtenção do resultado desejado. O prognóstico dos pacientes evolui positivamente, com resolução ou melhora total da dor, mas ainda sendo necessário seguimento fisioterápico, e resolução do quadro infeccioso original que teve como resultado a discite.

\section{Referências}

1. Garcia EC, Braga CA, Ferreira CAL, Mendes GS. Espondilodiscite: um diagnóstico diferencial raro de dor abdominal. RevMed Minas Gerais 2013; 23(3): 392-5.

2. Gouliouris T, Aliyu SH, Brown NM. Spondylodiscitis: update on diagnosis and management. J AntimicrobChemother. 2010; 65(Suppl 3)1124.

3. Patel P, Olive KE, Krishnan K. Septic discitis: an important cause of back pain. South Med J. 2003; 96:692-695.

4. Modic MT, Feiglin DH, Piraino DW. Vertebral osteomyelitis: assessment using MR. Radiology. 1985; 157:157-66.

5. Parra JLC, Martin ASA, Martinez-Aedo AL, Ivanez IS, Agreda E, Stern LLD. Management of infectious discitis. Outcome in one hundred and eight patients in a University Hospital. IntOrthop. 2012; 36: 239-244.

6. Lillie P, Thaker H, Moss P. Healthcare associated discitis in the era of antimicrobial resistance. J ClinRheumatol. 2008; 14:234-7.

7. Mylona E, Samarkos M, Kakalou E. Pyogenic vertebral osteomyelitis: a systematic review of clinical characteristics. SeminArthritisRheum. 2009; 
39: $10-7$.

8. Lima ACT, Almeida GDS, Nunes LDO, Dos Santos LP, Santo

RJMDE. Espondilodiscite Tuberculosa: Relato de Caso Clínico e Revisão de

Literatura. Anais Eletrônico CIC. 2019; 17(17).

9. Carvalho VN, SilvaFF, Sarmento PM, Baptista S, SáJ.Espondilodiscite Infecciosa: Formas de Apresentação, Diagnóstico e Tratamento. Medicina Interna. 2018; 25(2): 85-90.

10. Sociedade Brasileira de Medicina Hiperbárica. Diretrizes de Uso da Oxigenoterapia Hiperbárica. Florianópolis, SC; 2019. 39p. 